\title{
Alguns aspectos sobre o processo de aquisição da escrita por uma criança pequena com Síndrome de Down
}

\author{
Ingrid Anelise Lopes*
}

Anna Augusta Sampaio de Oliveira**

\section{Resumo}

A cultura é o conteúdo da Educação Infantil, qual deve ser ensinado por meio de planejamento e procedimentos pedagógicos adequados à criança pequena, quais devem propiciar vivências de instrumentos da cultura. Tais vivências permitem o pleno desenvolvimento de todas as crianças. Isso inclui a criança com necessidades educacionais especiais decorrentes da síndrome de Down. Dentre outros instrumentos da cultura, a criança pequena precisa vivenciar a escrita para que inicie o seu processo histórico de aquisição dessa linguagem. Ao observarmos crianças com síndrome de Down alijadas de vivências da escrita na Educação Infantil, realizamos uma investigação, com base na Teoria Histórico-Cultural, com o objetivo de descrever e compreender os sentidos atribuídos à escrita, por uma criança pequena com síndrome de Down. Os dados foram coletados por meio de registros das vivências da escrita por esta criança junto à atuação de umas das pesquisadoras. A atuação ocorreu em sessôes de Atendimento Pedagógico de Suporte, que foram filmadas, com o apoio de auxiliares de pesquisa, e posteriormente observadas e descritas para a seleção de episódios a serem discutidos. Os dados foram apresentados e discutidos de modo a compreender possíveis sentidos atribuídos à escrita pela criança. Os resultados apontam que a criança atribuiu sentidos à escrita, e que tal atribuição esteve diretamente relacionada com a significação da escrita pelas pesquisadoras, nos atendimentos. Assim, foi possível compreender que os sentidos atribuídos à escrita têm estreita relaçáo com o processo de mediaçáo.

Palavras-chave: Educação Infantil. Escrita. Síndrome de Down.

\footnotetext{
* Doutoranda do Programa de Pós-Graduação Educação pela Universidade de São Paulo (USP). Mestre em Educação pela Universidade Estadual Paulista Júlio de Mesquita Filho (UNESP). Professora de Educação Básica na Secretaria Municipal de Educação de Diadema, São Paulo. ** Doutora em Educação Universidade Estadual Paulista Júlio de Mesquita Filho (UNESP). Professora do Departamento de Educação Especial e do Porgram de Pós-Graduação na UNESP.
} 


\section{Introdução}

No Brasil, a trajetória do atendimento institucional à criança pequena se configurou por diferentes características, todas vinculadas às concepçóes ideológicas que determinaram os paradigmas políticos do país (KRAMER, 2006).

Merisse (1997) divide a história do atendimento à criança pequena, em nosso país, em quatro fases: 1) Instituiçóes exclusivamente filantrópicas; 2) Instituiçôes com preocupação e orientação higiênico-sanitária; 3) Instituições com caráter assistencial; e 4) Instituiçôes com caráter educacional.

Atualmente, o atendimento à criança pequena no Brasil é orientado, em termos legais, por instituiçóes de caráter educacional, atendimento que constitui uma etapa da educação básica, a Educação Infantil (BRASIL, 1996).

A Educação Infantil compreende o atendimento educacional da criança na faixa etária entre os primeiros meses de vida aos cinco anos de idade, e está organizada em duas partes: creches, para crianças pequeninas dos primeiros meses de vida aos três anos, e pré-escola, para crianças pequenas, de quatro a cinco anos de idade.

A partir da promulgação da Lei $\mathrm{n}^{\circ} 11.274$, de 6 de fevereiro de 2006 (BRASIL, 2006), que torna obrigatório o ensino fundamental de nove anos, quando refletimos sobre o atendimento educacional à criança pequena, remetemo-nos àquela entre os primeiros meses até os cinco anos de idade, $\mathrm{e}$ não mais até os seis anos. Assim, com a instituição dessa lei, a criança brasileira passou a ingressar no ensino fundamental aos seis anos de idade, enquanto a Educaçáo Infantil passou a atender crianças dos primeiros meses aos cinco anos de idade.

A atual política para a Educação Infantil apresenta diversos norteadores, dentre os quais destacamos: a compreensão de Educação Infantil como primeira etapa da educação básica e direito da criança; a compreensão de currículo da Educação Infantil como norteador do desenvolvimento integral da criança, promovendo a ampliação de suas experiências e conhecimentos, contemplando a diversidade social e cultural, e os conhecimentos que se pretende universalizar; e a compreensão de que a criança com necessidades educacionais especiais deve estar matriculada, sempre que possível, na rede regular de ensino (LEITE FILHO, 2001). A criança com necessidades educacionais especiais é compreendida como aquela com deficiência, transtornos globais do desenvolvimento ou altas habilidades/superdotação (BRASIL, 2008). 
A compreensão da Educação Infantil como primeira etapa da educação básica e direito da criança confere à creche e à pré-escola espaços de ensino sistematizado, sendo mediadores das esferas cotidianas e não cotidianas do conhecimento (ARCE; MARTINS, 2007) ${ }^{1}$. Nesse sentido, a função essencial da Educação Infantil "[...] é a socialização do saber científico, artístico, cultural, ético, etc. tendo em vista o pleno exercício das possibilidades humanas e seguramente essa função não será desempenhada nos estreitos limites da cotidianidade" (ARCE; MARTINS, 2007, p. 59).

Compreender a Educação Infantil como espaço de ensino sistematizado não significa que essa etapa da educação deva antecipar o ensino característico do ensino fundamental. Significa que o ensino à criança pequena deve ocorrer em "[...] contextos de aprendizagem e desenvolvimento, sustentados pelo planejamento de conteúdos e procedimentos de ensino adequados à faixa etária a que se destinam" (ARCE; MARTINS, 2007, p. 61, grifo nosso).

Em outras palavras, o ensino na Educação Infantil deve ser sistematizado por meio de estratégias de ensino: materiais, tempo, espaço e conteúdos adequados à criança, de modo que ela possa vivenciar a cultura humana e se expressar por diferentes linguagens.

Embora, quando mencionamos "conteúdos e procedimentos de ensino para a Educação Infantil”, haja o risco de sugerirmos a antecipação do ensino, concordamos com Arce e Martins (2007), que, para a Educação Infantil, há conteúdos e procedimentos específicos de ensino que não se confundem com aqueles destinados aos anos iniciais do ensino fundamental.

\section{Ensino e Educação Infantil: o acesso à cultura}

O conteúdo de ensino da Educação Infantil é a cultura, constituída dos instrumentos materiais e não materiais produzidos ao longo da história da humanidade. A cultura como conteúdo da Educação Infantil - que respeita à infância - deve ser instrumento dessa etapa da educação, pelo planejamento e procedimento adequado à criança pequena, que é propiciar-lhe a vivência da necessidade dos instrumentos da cultura, da significação desses instrumentos.

Inserida na cultura, na vivência cotidiana de seus significados, a criança poderá desenvolver a necessidade de se inserir na cultura - cultura como fonte das qualidades humanas -, ou seja, como formação das funçôes psíquicas superiores; a criança poderá desenvolver a necessidade de falar, andar, brincar, 
cantar, dançar, contar, pintar, desenhar, construir, imaginar, encenar, criar, calcular, ler, escrever etc. É dessa forma que se apropriará da cultura, porque sentirá necessidade de vivenciar as diferentes expressōes do modo de viver e ser das pessoas que estão em seu entorno (tudo o que envolve a vivência da criança).

Nesse sentido, a especificidade do ensino na Educação Infantil é promover à criança vivências da cultura por meio de diferentes linguagens, entendendo por vivência infantil tudo aquilo que a criança faz em seu tempo de vida, e que é por meio das vivências que a criança aprende e se desenvolve.

Compreendemos o desenvolvimento humano para além da natureza biológica - a partir dos pressupostos da Teoria Histórico-Cultural, que é uma vertente da psicologia soviética que tem como expoentes Lev Semenovitch Vygotsky (1986-1934), Alexei Nikolaevich Leontiev (1903-1979) e Alexander Romanovich Luria (1902-1977)2.

Na perspectiva dessa Teoria, o desenvolvimento é configurado mediante a apropriação das qualidades especificamente humanas, o que ocorre por meio da educaçấo e das condiçôes concretas de vida (LEONTIEV, 2006; VYGOTSKI, 1995). Por isso, Vygotski (1997) assinala que a criança tem dois nascimentos: um natural e outro cultural, respectivamente, atrelados às "funçôes psíquicas elementares" e às "funçōes psíquicas superiores". As funçóes psíquicas elementares fazem parte da herança biológica da criança, estão dadas ao nascer, e são desenvolvidas no curso da "filogênese" (desenvolvimento da espécie humana). Já as funçôes psíquicas superiores correspondem a todas as características especificamente humanas (culturais), e derivam do percurso histórico e cultural da educação e das condiçóes concretas de vida da criança, da "ontogênese" (desenvolvimento do sujeito humano) (VYGOTSKI, 1995). Vale apontar que, ainda que sejam dois tipos de funçóes psíquicas, elas são interdependentes.

Para que haja formação e desenvolvimento das funçóes psíquicas superiores, Vygotski (1995) esclarece que a criança precisa realizar atividades psíquicas, por intermédio da internalização, que ocorre por meio de dois processos, os "interpsíquicos" (interpessoais) e os "intrapsíquicos" (intrapessoais).

Esse processo de internalização, pelo qual a criança aprende e se desenvolve, consiste na lei genética geral do desenvolvimento humano e está submetido à educação e às condições concretas de vida, portanto, aos diferentes momentos históricos da vida da criança. 
No seu processo de desenvolvimento, a criança passa por diferentes momentos históricos, estágios ou "períodos sensitivos", que caracterizam seu desenvolvimento e desempenham um papel diretivo nesse desenvolvimento. Cada período foi definido por Leontiev (2006, p. 65) como uma forma específica de relação da criança com o seu entorno, forma denominada "atividade principal”, que corresponde à "[...] atividade cujo desenvolvimento governa as mudanças mais importantes nos processos psíquicos e nos traços psicológicos da personalidade da criança, em certo estágio do seu desenvolvimento". Desse modo, em cada etapa do desenvolvimento da criança há uma atividade principal específica, que impulsiona o seu desenvolvimento. No entanto, ressalta o autor:

[...] embora notemos um certo caráter periódico no desenvolvimento da psique da criança, o conteúdo dos estágios, entretanto, não é, de forma alguma, independente das condiçôes concretas nas quais ocorre o desenvolvimento. É dessas condiçôes que esse conteúdo depende primariamente. (LEONTIEV, 2006, p. 65).

Na última etapa da Educação Infantil (a pré-escola), a atividade principal da criança pequena é a brincadeira de faz de conta. É por meio dela que a criança pequena se apropria da cultura (fonte das qualidades especificamente humanas). Além da atividade principal, outras atividades (secundárias) promovem o desenvolvimento infantil, denominadas "formas produtivas de atividade" ou "atividades produtivas", que são todas aquelas das quais derivam um produto, como, por exemplo, desenhar, pintar, modelar, construir, recortar, colar (MUKHINA, 1995). Essas atividades (tanto a principal quanto as secundárias) são atividades socialmente mediadas.

É por intermédio de atividades socialmente mediadas que a criança desenvolve suas funçôes psíquicas superiores (que são funçóes culturais), como a atenção voluntária, a memória lógica, a linguagem, o desenho, a escrita, o cálculo, a formação de conceitos etc. (VYGOTSKI, 1995).

Elas [as funções culturais] surgem como resultado da progressiva inserção da criança nas práticas sociais do seu meio cultural onde, graças à mediação do Outro, vai adquirindo a sua forma humana, à semelhança dos outros homens. Portanto, diferentemente do que ocorre com as funçôes biológicas, que se inscrevem nas estruturas 
genéticas da espécie, as culturais inscrevem-se na história social dos homens. (PINO, 2005, p. 32, grifo do autor).

O papel do Outro, nesse sentido, é imprescindível ao desenvolvimento humano. Na Educação Infantil, desempenham o papel do Outro, para a criança, todos os adultos e as demais crianças da escola. São esses que, nas vivências, atuam no processo de mediação semiótica (contato mediado por signos) e de mediação instrumental, de inserção cultural da criança. E, "[...] na medida em que as ações da criança vão recebendo a significação que lhe dá o Outro - nos termos propostos pela tradição cultural do seu meio social - ela vai incorporando a cultura que a constitui como ser cultural, ou seja, como um ser humano" (PINO, 2005, p. 66, grifo do autor).

Nesse processo, o Outro atua, por exemplo, ao atribuir o sentido de bola a uma linha curva fechada desenhada por uma criança que não tem a intenção de representar algo, pois "[...] funçôes naturais só se tornam significativas para a criança graças à mediação do Outro que lhes atribui a significação" (PINO, 2005, p. 100).

Embora o Outro tenha papel insubstituível, o processo de mediação não corresponde somente a sua atuação, mas também ao uso de signos pela criança, uma vez que a mediação é um processo de significação da cultura, significação que é criação e uso de signos (PINO, 2005). Assim, o processo de mediação é estabelecido na relação em que a criança atribui sentido à cultura, a partir da significação estabelecida pelo Outro, uma vez que, a partir de Pino (2005), por significação, compreendemos a utilização social dos signos. E, por sentido, o emprego pessoal dos signos.

O processo de mediação não ocorre porque Outro está junto da criança, e náo corresponde ao que o Outro diz ou mostra à criança apenas, mas ao sentido que as açôes dos Outro tem para ela. A mediação é, assim, o processo em que o Outro significa à cultura, e o sentido que a criança atribui; sentido da criança à significação do Outro.

É importante destacar que o sentido que a criança atribui à cultura lhe é próprio, relacionado à sua vivência e não exatamente aquele atribuído pelo Outro. Isso porque a atribuição de sentido pela criança não é automática em relação à atuação do Outro, porque não há coincidência entre o tempo de ensino e o tempo de aprendizagem, pois o desenvolvimento tem uma lógica interna e náo está subordinado ao programa escolar. A mediaçáo, dessa maneira, náo 
é imediata: quando o professor ensina, a criança apenas inicia a elaboração do conceito (VYGOTSKI, 1993).

Desse modo, a mediação ocorre somente porque a criança atribui sentido à cultura a partir da significação do Outro. É um processo que inter-relaciona significaçấo e sentido. O problema está em identificar os significados atribuídos pelas crianças.

Por isso, embora, nas escolas, a palavra "mediação" tenha sido conceituada como açôes do professor e da professora, não é possível afirmar, por exemplo, que um professor mediou a escrita à criança porque apresentou formas de escrita ou escreveu, sem relacionar a ação do professor com o sentido atribuído à escrita pela criança.

Para compreender o processo de mediação, é imprescindível relacionar a significação ao sentido. Diferentemente do que conceitua a Teoria HistóricoCultural sobre o processo de mediação, muitos são aqueles que o compreendem como o auxílio prestado pelo professor à criança, na realizaçáo de tarefas, o fazer junto, a oferta de materiais, a organização do espaço, independentemente do sentido que a criança atribui a todas essas açóes. Isso tem se desdobrado para propostas pedagógicas sem atenção à significação do professor, e consequentemente, ao sentido atribuído pela criança.

A proposta pedagógica, que é também aspecto da mediação, pode levar a criança a atribuir diferentes sentidos aos instrumentos da cultura vivenciados na escola de Educação Infantil. Quando esses instrumentos são vivenciados pela criança como necessários, a criança pode atribuir aos instrumentos o sentido de que eles são necessários. Sem essa vivência, a criança pode não compreendê-los como necessários.

No processo de mediação, o professor busca levar a criança a atribuir sentidos aos objetos da cultura humana (fonte das funçôes psíquicas superiores), por meio de sua significação. Em decorrência, a mediação acontece quando, com a atuação do Outro, a criança cria e/ou interpreta signos, quando ela atribui sentidos à cultura, quando sabe e pode dizer a respeito do conjunto das produçóes humanas (PINO, 2005). "O acesso ao universo da significaçáo implica, necessariamente a apropriação dos meios de acesso a esse universo, ou seja, dos sistemas semióticos criados pelo homem ao longo da sua história, principalmente a linguagem, sob suas várias formas." (PINO, 2005, p. 59). 
Isso quer dizer que a inserção cultural da criança passa necessariamente por dupla significação: "[...] a dos signos e a do Outro, detentor da significaçáo" (PINO, 2005, p. 59). Portanto, o caminho que leva a criança ao mundo e este à criança passa pelo Outro, mediador entre a criança e o universo cultural.

No processo de aprendizagem e desenvolvimento da criança, o professor tem papel fundamental, que é o de atuar no processo de mediação, ao significar a cultura vivenciada pela criança, de modo que possibilite a ela igualmente atribuir sentidos e ter a necessidade de conhecer o mundo e se expressar por diferentes linguagens.

Para atuar nesse processo, o professor não deve realizar tarefas (com os instrumentos da cultura, como a dança, a pintura, o desenho, a escrita etc.) pela e nem para a criança, mas com a criança - atuando como parceiro mais experiente, $\mathrm{e}$ não em seu lugar, tal como escreve Mello (2003), a partir dos estudos de Vygotski (1995). "Quando uma criança realiza - com a ajuda de um educador - tarefas que superam seu nível de desenvolvimento, ela se prepara para realizá-las sozinha, pois, o aprendizado cria processos de desenvolvimento que, aos poucos, vão se tornando parte de suas possibilidades reais" (MELLO, 2003, p. 6).

Ao fazer junto à criança, o professor significa ações da criança e atua em um aspecto fundamental do desenvolvimento infantil, o qual Vygotski (1995) denominou "zona de desenvolvimento iminente", correspondente ao que a criança faz com ajuda de um parceiro mais experiente. O que a criança realiza com independência é denominado, pelo autor, de "zona de desenvolvimento atual".

Ao oferecer à criança vivências da cultura, é preciso considerar as características do desenvolvimento infantil, o que não significa modificar a forma nem mesmo a função social do instrumento da cultura que lhe é ensinado, porque a cultura deve ser vivenciada pela criança na sua forma ideal. Como alerta Vygotsky (1994, p. 18), “[...] se não houver nenhuma interação como a forma ideal final, esta forma devida deixará de se desenvolver devidamente na criança”. Ainda, segundo o autor,

[...] no desenvolvimento da criança o que é possível conseguir ao final e como resultado do processo de desenvolvimento está presente já no entorno desde o princípio do desenvolvimento infantil [...] [em sua forma final ou ideal,] ideal no sentido de que atua como modelo do que se deve conseguir ao final do processo de desenvolvimento. (VYGOTSKY, 1994, p. 14). 
Isso significa que o "entorno é fonte de desenvolvimento" (VYGOTSKY, 1994). No entorno, encontramos as características e as formas de atividades superiores especificamente humanas. Por isso, o autor explica que a criança aprende a falar vivenciando a fala, a partir da referência da linguagem oral em toda a sua complexidade, e náo de suas partes isoladas e, sobretudo, como uma necessidade para a criança.

Nessa perspectiva, em uma sociedade como a nossa, na qual a linguagem escrita é instrumento cultural de uso diário por muitas pessoas, a criança pode iniciar o seu processo de aquisição da escrita ao vivenciar essa linguagem também na Educação Infantil, ao observar, testar, brincar, imitar a escrita. Com efeito, nessa etapa da educação, a escrita precisa ser instrumento de expressão da criança (quando Outro escreve por, para ou junto à criança), como uma complexa atividade cultural, e não um hábito motor determinado - mas como uma necessidade. Nas palavras do Vygotski (1995, p. 201, grifo nosso):

Nós não negamos que seja possível ensinar a ler e a escrever a crianças de idade pré-escolar, inclusive consideramos conveniente que a criança saiba já ler e escrever ao ingressar na escola. Porém, o ensino deve organizar-se de forma que a leitura e a escrita sejam necessárias de algum modo para a criança.

Compreendemos que a escrita pode e deve ser ensinada desde a préescola, ao considerar que, no processo de aquisição da escrita, a criança tem a sua "história da escrita" vinculada ao desenvolvimento das suas necessidades e da sua atividade principal. A "história da escrita da criança", assim denominada por Vygotski (1995), refere-se ao processo de aquisição da escrita, que tem início antes de a criança ingressar na escola, principiado pela vivência desse instrumento da cultura como uma necessidade, bem como pela aquisiçáo de habilidades constituintes das bases orientadoras dessa linguagem, como o gesto expresso pelo desenho e pela brincadeira de faz de conta.

Com essa perspectiva, na Educação Infantil é necessário promover à criança pequena o desenvolvimento da necessidade de se expressar também por meio da escrita - sem deixar de ofertar todas as demais linguagens, pois, como apresentaremos a seguir, na pré-história da escrita, as diferentes formas de expressão da criança levam-na à aquisição da escrita. A necessidade dessa linguagem precisa ser desenvolvida com base em vivências com a forma ideal 
da escrita, tendo em vista, sobretudo, a atividade principal da criança pequena, a brincadeira de faz de conta.

A atividade principal, assim como as atividades secundárias, são todas bases orientadoras para a aquisição da escrita, ou seja, são atividades que levam a criança ao desenvolvimento de atividades psíquicas necessárias para a aquisição da escrita, atividades como aquelas promovidas pelo desenho e pela brincadeira de faz de conta.

Vygotsky (1995, p. 192) assinala que "[...] o desenho infantil é uma etapa prévia da escrita. Por sua função psicológica, o desenho infantil é uma linguagem gráfica peculiar, um relato gráfico sobre algo [...] uma forma peculiar de escrita". O desenho é, assim, aspecto do "nexo genético" (processual) entre o gesto e o signo escrito.

Para o autor, além do desenho, os jogos infantis ou brincadeiras de faz de conta fazem igualmente parte desse nexo, porque os jogos infantis, assim como o desenho, são gestos representativos (anotaçôes simbólicas objetais); "[...] durante os jogos os objetos passam a significar muito facilmente outros, os substituem, se convertem em signos seus." (VYGOTSKI, 1995, p. 187). Assim como com o desenho, com a brincadeira de faz de conta a criança desenvolve a representação simbólica - atividade psíquica superior também necessária para a aquisição da escrita.

Em outras palavras, tanto o desenho quanto o faz de conta constituem-se como elos essenciais entre o gesto e a escrita. Em ambas as atividades, a criança explora a representação do real, o simbolismo, entendido como um aspecto fundamental da escrita, haja vista que a representação simbólica explorada no desenho e no jogo de faz de conta é, na essência, uma forma peculiar de linguagem que leva à escrita (VYGOSTSKI, 1995).

Na história da escrita da criança, ela percorre uma trajetória de aprendizagens fundamentais para se apropriar da escrita. Inicialmente, a grafia indica uma linguagem imitativa. Gradualmente, passa a ser utilizada como simbolização direta da realidade. Entretanto, essa passagem não é automática. Ela ocorre somente por meio de diferentes significaçóes que o Outro atribui à escrita, de modo que a criança pequena possa atribuir sentidos à escrita também. A escrita deve ser ensinada de modo que se realize essa passagem. Sem a atuaçáo do professor voltada para isso, a criança pode aprender a atribuir à escrita somente o sentido de uma linguagem que representa a fala (a relação entre som 
e letra), e manter esse sentido. Isso se dá quando o ensino é fixado no aspecto técnico da escrita, e se segue por ele enfatizando a ortografia e a gramática - e não a expressão, por exemplo (VYGOTSKY, 1995; LURIA, 2006).

Ao compreender a escrita como instrumento auxiliar da memória, Luria (2006) organiza essa trajetória em quatro estágios: 1) Estágio pré-instrumental, quando escrever é uma brincadeira, um ato imitativo, que não mantém relação funcional com a escrita; 2) Estágio da escrita topográfica, quando a escrita indica algum significado, mas ainda não determina qual seja, sendo caracterizada por um signo primário não diferenciado; 3) Estágio da escrita pictográfica, quando escrever expressa um signo simbólico, mas não convencional; 4) Estágio da escrita simbólica, quando a escrita é representada por seus signos convencionais atrelados aos significados e ao desejo de expressão ou auxílio mnemônico. Assim, no processo de aprendizagem da escrita, a criança aprende diferentes formas de escrever.

Vale apontar que não é possível fixar uma linha etária divisória definitiva e um curso evolucionista para esses estágios, pois eles dependem de uma gama de condiçóes concretas relacionadas com o nível de desenvolvimento cultural e o ambiente onde a criança vive (LURIA, 2006).

Segundo Luria (2006), o fator responsável pela mudança dos estágios é a atuação do Outro, que leva a criança a observar o conteúdo da escrita, expresso na quantidade e na forma. A série de invençóes que conduz a criança para um novo estágio acontece com o uso cultural dos signos, uma vez que não é a compreensão que gera o ato, mas, frequentemente, é o ato que gera a compreensão (LURIA, 2006). Desse modo, entendemos que, na amplitude do processo de aquisição da escrita,

[...] a criança tendo constituído as bases necessárias da função simbólica da consciência enquanto se expressa por intermédio do desenho e do jogo de faz-de-conta, aprende que pode se expressar também pela escrita mediada pela linguagem oral e a partir disto, vai formulando hipóteses sobre a escrita como um signo independente que simboliza a realidade e vai internalizando a linguagem e sua forma expressiva mais elaborada o que exige do sujeito novos modos de pensar e de agir. (LIMA, 2005, p. 142).

Diversos estudos contemporâneos, com base na Teoria Histórico-Cultural, indicam que, na pré-escola, a criança pequena precisa vivenciar a escrita como 
uma das formas de expressão - sobretudo, como uma necessidade (LIMA, 2005; MELLO, 2006; VIEIRA, 2006; VALIENGO, 2008).

É importante ressaltar que, nesses estudos, a escrita é compreendida como um instrumento cultural simbólico complexo, não reduzido à codificação e ou à decodificaçẫo de letras e ou palavras. Vivências com essa linguagem, nesse sentido, abrangem a expressão infantil por meio da dimensão simbólica que envolve a escrita e, sobretudo, a escrita como um instrumento necessário.

A importância de a criança vivenciar a escrita como um instrumento necessário, assim como as demais formas de linguagem na Educação Infantil, não significa que se deva antecipar a escolarização da criança negando-lhe a infância. De outro modo, por meio da consideração da atividade principal da criança, que é a brincadeira de faz de conta e as atividades produtivas, a Educaçáo Infantil deve garantir e cultivar o desejo de expressão da criança, a vivência da escrita como um instrumento necessário e promover o desenvolvimento da necessidade de novas aprendizagens (MELLO, 2003, 2006; LIMA, 2005; VIEIRA, 2006; VALIENGO, 2008).

A vivência da escrita na Educação Infantil, como já afirmamos, deve se dar por meio da função social dessa linguagem, que deve ser apresentada em sua forma ideal, porque a primeira sem a segunda pode ensinar à criança atribuir diferentes sentidos à escrita, e talvez não o sentido de um instrumento necessário - papel para o qual foi criada.

Em síntese,

De acordo com a Teoria Histórico-Cultural, a criança é um sujeito com uma ilimitada capacidade de aprender. Ela aprende utilizando os objetos da cultura pela própria atividade: utilizando a escrita, portanto, para o fim para o qual esse sistema lingüístico foi criado. [...] Para que a aprendizagem da escrita se inicie, a criança precisa viver a atividade de escrever para relembrar, para comunicar um recado, para relatar um passeio, para registrar atividades que realiza, para expressar emoçóes, conhecimentos. (LIMA, 2008, p. 2, grifo nosso).

Pensamos até aqui sobre a escola de Educação Infantil como uma instituição educacional que deve promover o ensino sistematizado que respeite a infância, proporcionar à criança pequena, dentre as diversas vivências, também 
a vivência da escrita, por compreender, a partir da Teoria Histórico-Cultural, que sem essa vivência pode não se apropriar desse instrumento da cultura.

\section{A vivência da escrita na Educação Infantil pela criança pequena com Síndrome de Down}

Por meio de diferentes linguagens, e consideradas as peculiaridades do desenvolvimento infantil, é que a criança forma as bases orientadoras para a aquisiçâo da escrita, constituindo a sua pré-história da escrita desde que vivencie a escrita, ao que vale enfatizar devido à especificidade da investigação; sem desconsiderar a necessidade da criança brincar, cantar, dançar, correr, pular, pintar, desenhar, dramatizar, dentre as demais atividades infantis.

Ao considerarmos que é por meio de vivências com a linguagem escrita que a criança inicia a aquisiçáo dessa linguagem, perguntamo-nos: quem deve vivenciar a escrita na Educaçáo Infantil? Pelo exposto até aqui, respondemos: toda criança que dessa educaçáo se beneficia. Parece-nos óbvia essa colocação, mas ela se faz importante diante do atual movimento e momento histórico da educação brasileira.

$\mathrm{Na}$ atual política da Educação Infantil no Brasil há a compreensão de que a criança com deficiência deve estar matriculada, sempre que possível, na rede regular de ensino. A política para a Educação Infantil assume, portanto, o compromisso de possibilitar o pleno desenvolvimento de todas as crianças, desde os primeiros meses de vida até os cinco anos de idade. Isso inclui a criança com necessidades educacionais especiais decorrentes da síndrome de Down. Essa síndrome, dentre outras características, compromete o desenvolvimento intelectual das crianças, desencadeando, assim, um quadro de deficiência intelectual (SCHWARTZMAN, 1999). O sistema de 2002 da Associação Americana de Retardo Mental (atual Associação Americana de Deficiência Intelectual e do Desenvolvimento) conceitua a deficiência intelectual como a "[...] deficiência caracterizada por limitaçóes significativas no funcionamento intelectual da pessoa e no seu comportamento adaptativo - habilidades práticas, sociais e conceituais - originando-se antes dos dezoito anos de idade" (AAMR, 2006, p. 8).

Tendo em vista a política para a Educação Infantil, podemos afirmar que a criança com síndrome de Down deve igualmente participar da Educação Infantil e se beneficiar da cultura vivenciada pela criança nesse contexto, sendo assim, também da escrita. 
Ao levar em conta que, na Educação Infantil, são formadas as bases orientadoras para a aquisição da escrita pela criança (VYGOTSKI, 1995; LURIA, 2006) e que a criança com síndrome de Down aprende a ler e a escrever, desde que, no processo de sua educação, haja adequado ensino (IDE, 1992; BONETI, 1999; MERCADO, 2000; GOMES, 2001; GÂNDARA, 2005; LOPES, 2011), pode-se afirmar que, desde a Educação Infantil, é necessário que a escrita seja vivenciada em sua forma ideal - como necessidade - pela criança com síndrome de Down, para que ela perpasse o processo histórico de aquisição dessa linguagem.

Vygotski (1997) esclarece que, embora o desenvolvimento da criança com deficiência apresente diferenças qualitativas, ele é determinado pela "lei genética geral do desenvolvimento humano". Isso significa que a criança com deficiência se desenvolve e se constitui como sujeito humano pelos mesmos processos que são constitutivos do desenvolvimento de qualquer outra criança (FERREIRA, 2002). Por isso, a criança com deficiência - assim como a criança não acometida pela deficiência, conforme mencionamos anteriormente - tem dois nascimentos: o nascimento natural, de caráter biológico, que é marcado pela deficiência primária, e o nascimento cultural, que, a partir das relaçóes que a criança estabelece com o outro, pode ser determinado como deficiente (VYGOTSKI, 1997) ou pode humanizar a criança (PADILHA, 2005). A deficiência primária se caracteriza pelo prejuízo de ordem biológica. Esse prejuízo diante de uma determinada organizaçáo social e cultural pode ser ratificado, levando à deficiência secundária, esta de ordem social, que se estabelece nas interpretaçôes e relaçóes instituídas entre o grupo social e a pessoa que apresenta a deficiência (VYGOTSKI, 1997).

Nesse sentido, "[...] o processo de constituição humana, através da apropriação dos bens culturais e simbólicos historicamente acumulados, não se dá de forma natural, mas, ao contrário, é um processo carregado de intencionalidade" (OLIVEIRA, 2007, p. 70).

Essa compreensão não nega a deficiência primária, porém ressalta que, embora haja peculiaridades no desenvolvimento da criança com deficiência, o seu desenvolvimento é determinado pela educação e pelas condiçôes concretas de vida (CARLO, 2001; PADILHA, 2005; PINTO; GÓES, 2006; OLIVEIRA, 2007).

Isso quer dizer que as relaçóes sociais podem mediar o processo de "compensação" e inserir a criança no mundo cultural. Compensaçấo é "[...] 
precisamente a linha diretriz do desenvolvimento da criança com deficiência em alguma função ou órgão [...]" (VYGOTSKI, 1997, p. 48); são os processos substitutivos que medeiam o desenvolvimento, surgidos pelas dificuldades objetivas com as quais se deparam a criança com deficiência em processo de desenvolvimento.

De outro modo, as relaçôes sociais podem também dificultar ou impedir o desenvolvimento de funçôes psíquicas superiores, prejudicando, assim, o desenvolvimento cultural da criança com deficiência (VYGOTSKI, 1997). Sendo o desenvolvimento da criança com deficiência determinado pela lei genética geral do desenvolvimento humano, o seu desenvolvimento é guiado por suas atividades, como é para qualquer outra criança.

Considerando, a partir da "história da escrita da criança", que, no percurso do seu desenvolvimento, ela precisa vivenciar a escrita como uma necessidade na Educação Infantil, as propostas pedagógicas devem ser orientadas no sentido de promover tais vivências à criança pequena com síndrome de Down.

No entanto, não é raro observar que em algumas escolas de Educação Infantil, a escrita não é vivenciada pelas crianças, como uma necessidade nem como uma linguagem porque é tratada como instrumento de codificação e decodificação, compreendido e expresso por hábitos visuais e motores. Não é raro também, observar nessas escolas crianças pequenas com síndrome de Down alijadas da vivência da escrita.

Isso nos coloca diante de um problema pedagógico: há professoras que não permitem à criança pequena com síndrome de Down vivências com a escrita na Educação Infantil. Problema este que nos leva a seguinte consideração: há crianças pequenas com síndrome de Down alijadas da vivência da escrita por se pensar que elas não atribuem quaisquer sentidos à escrita.

Essa consideraçâo nos leva a alguns questionamentos: ao vivenciar a escrita, a criança pequena com síndrome de Down atribui sentido à escrita? Quais sentidos ela atribui e manifesta? O que e como ela manifesta podem nos sugerir tais sentidos? Afinal, quais são os sentidos atribuídos à escrita por uma criança pequena com síndrome de Down?

A partir destes questionamentos, realizamos uma investigação com o objetivo de descrever e compreender os sentidos atribuídos à escrita, por crianças pequenas com síndrome de Down, bem como caracterizar a atuação pedagógica empregada em vivências da escrita por tais crianças. 
Os dados da pesquisa foram coletados no Centro de Estudos da Saúde e Educação (CEES), unidade auxiliar da Universidade Estadual Paulista "Júlio de Mesquita Filho" (UNESP), campus de Marília. A coleta ocorreu por meio de registros de possíveis sentidos atribuídos à escrita por crianças pequenas com síndrome de Down, e registros das ações de uma das pesquisadoras, a qual atuou junto às crianças. A atuação ocorreu em 22 sessóes de Atendimento Pedagógico de Suporte, nas quais foram propostas vivências da linguagem escrita para a criança. Todas as sessóes foram filmadas com o apoio de auxiliares de pesquisa, e posteriormente observadas para a seleção de episódios a contribuir à compreensão dos objetivos da pesquisa. Após a seleção, sete episódios foram transcritos e discutidos. Mariana é o nome fictício da criança (de seis anos de idade no momento do estudo) apresentada neste texto ${ }^{4}$. Sendo assim, abordamos, a seguir, um episódio, bem como a discussão elaborada a partir dele.

\section{Sentidos atribuídos à escrita por Mariana}

Aqui focalizamos um episódio, no qual Mariana e a pesquisadora escreveram um texto como parte de um estudo sobre o sistema solar, em decorrência de a criança demonstrar interesse por desenhos e brincadeiras com aspectos relacionados ao sistema (lua, estrelas, planetas e foguete). Em atendimentos anteriores, a pesquisadora e Mariana assistiram a um vídeo, e a pesquisadora leu informaçôes sobre o tema, em enciclopédias.

Nesse atendimento, Mariana ilustrou informaçóes sobre o sistema solar com desenhos, pinturas e colagens. Ao término da colagem, a pesquisadora apresentou a proposta a ser realizada: escrever um texto informativo sobre a exploração do sistema solar pelo homem.

Nesse episódio, a pesquisadora coloca uma folha sulfite sobre a mesa e solicita que Mariana ajude a escrever que o cachorro foi o primeiro ser vivo a viajar pelo espaço. Ela questiona Mariana: "você quer escrever ou eu escrevo?"; Mariana diz: "amassar, um barco", e passa a mão sobre a folha, sugerindo que quer fazer um barco. A pesquisadora diz que farão depois e insiste na atividade de escrita: "Vamos escrever aqui. Você escreve na sua folha e eu escrevo na minha". Então, diz Mariana: "cantar"; e a mesma postura é mantida pela pesquisadora informando que cantarão depois, e retoma a proposta da escrita.

Pesquisadora: Vamos escrever que o cachorro foi o primeiro ser vivo a viajar para o espaço, ó [pega a folha onde Mariana 
desenhou, pintou e colou imagens sobre o sistema solar e aponta à foto do cachorro]. Que é a Laika. Vamos colar aqui essa informação [aponta à folha].

Mariana: uau uau uau uau uau uau uau [imita um cachorro].

Pesquisadora: A Laika ó. Olha lá ela viajando no espaço [aponta à imagem]. Vou escrever aqui na minha folha. Escreve aí no seu [na sua folha].

Pesquisadora: [escreve ao pronunciar] OCA-CHOR-RO. Escreve ai no seu, o cachorro...

Mariana: [observa a escrita da pesquisadora enquanto pega outra caneta, na cor verde].

Pesquisadora: $O$ cachorro (escreve ao pronunciar) FO-IO-PRI-ME-I-RO.

Mariana: [traça linhas quebradas fechadas e abertas].

Pesquisadora: Você escreveu aí cachorro?

Mariana: [traça uma linha curva aberta e, ao terminar, olha para o desenho e pronuncia] CA-CHOR-RU.

Nesse episódio, Mariana inicialmente não demonstrou interesse pela proposta de escrita. A pesquisadora insistiu e informou a ela que, após a escrita, poderia fazer o que desejava, que era brincar e cantar.

Por essa interação, é possível inferir que Mariana afirmou e reiterou qual a sua atividade principal: a brincadeira. Enquanto isso, a pesquisadora apresentou a criança outra proposta, a escrita. É possível compreender a interação entre a pesquisadora e Mariana como uma espécie de negociação. Enquanto ela solicitou brincadeira, a pesquisadora insistiu que escrevesse.

Entretanto, não desconsiderou o interesse de Mariana e anunciou que seria atendido. Mas, para que fosse atendido, antes era necessário escrever. Após essa informaçáo, Mariana participou da proposta.

Ao esclarecer que depois brincariam e cantariam a pesquisadora atendeu à necessidade de Mariana, o que compreendemos como atuação pedagógica que auxiliou a criança a controlar a sua própria conduta, que é uma função psíquica superior, por isso também aprendida (VYGOTSKI, 1995). Certamente por compreender a dinâmica do atendimento, Mariana envolveu-se com a proposta e a realizou. 
Essa parte do episódio ilustra a relação entre o desenvolvimento de diferentes funções psíquicas superiores e sugere que a aquisição da escrita pela criança ocorre em estreita relação com o desenvolvimento de outras funçôes psíquicas superiores, e não como uma função isolada. As questôes a seguir ilustram essa compreensão.

Se Mariana náo soubesse a rotina do atendimento, conseguiria controlar a sua conduta e permanecer na atividade de escrita do modo como agiu? Se náo soubesse das brincadeiras posteriores à escrita, ela conseguiria controlar a sua conduta e realizar a proposta do modo como agiu? Certamente não.

$\mathrm{Na}$ sequência do episódio, a pesquisadora insistiu em solicitar a escrita à Mariana, e escreveu ao pronunciar, enquanto a criança observou. Depois, Mariana traçou linhas quebradas fechadas e abertas. E após, ao ser questionada pela pesquisadora - "você escreveu aí cachorro?"-, ela traçou uma linha curva aberta e, em seguida, silabou: “ $C A-C H O R-R U$ ”. Abaixo, segue a escrita de Mariana.

Figura 1 - Escrita da palavra cachorro

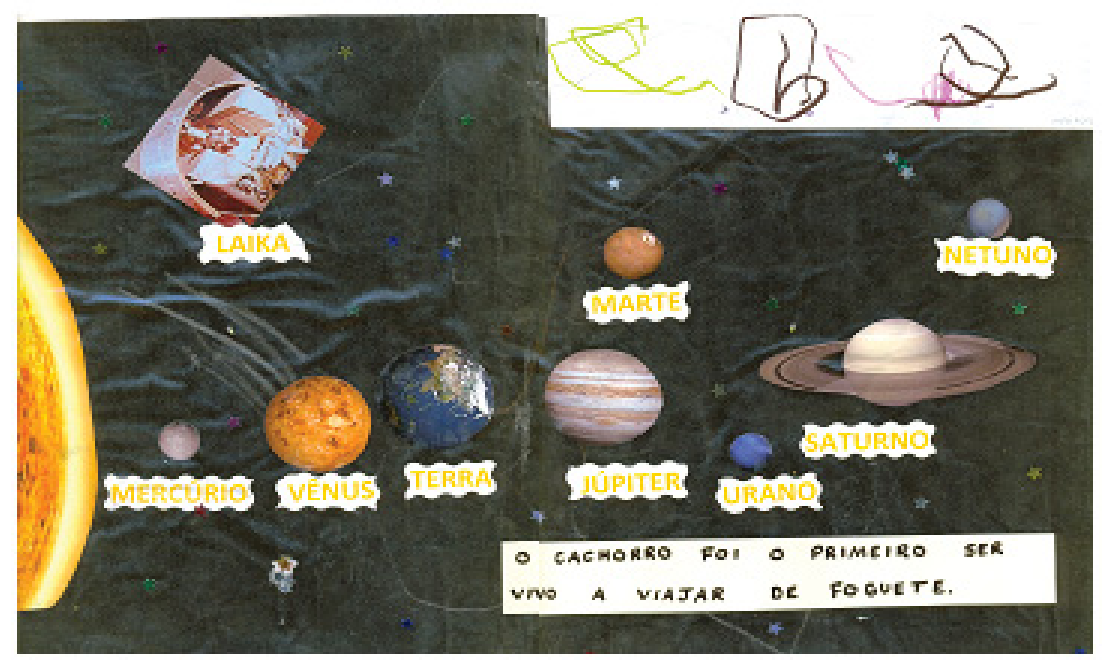

Fonte: LOPES, 2011, p. 50.

Ao perguntar "você escreveu cachorro?", a pesquisadora definiu a ação de Mariana - escrita. Ou seja, significou a ação da criança como forma de escrita, pois afirmou "você escreveu" e questionou se escreveu a palavra "cachorro", e náo se havia escrito. Ao questionar o que foi escrito não duvidou de que a criança 
escreveu. Assim, foi determinado o que Mariana fez - escrita -, embora não seja possível afirmar que Mariana atribuiu o mesmo sentido da significação. Contudo, é possível afirmar que Mariana demonstrou compreender que a escrita é uma representação que significa algo e que, para ser compreendida, precisa ser lida. Sendo assim, a escrita, nesse episódio, foi para Mariana um sistema especial de símbolos e signos, ainda que não representado por letra; foi representada pela forma de escrita de Mariana naquele momento: linhas quebradas e curvas.

Na sequência do episódio, ao considerar que Mariana, primeiro, observou a ação da pesquisadora (quando escreveu, ao pronunciar sílaba por sílaba) e, depois, Mariana leu a sua escrita, é possível inferir que Mariana reiterou a significação da pesquisadora e atribuiu o sentido de que escreveu.

A leitura (silabação) de Mariana sugere ser imitação da ação da pesquisadora, no episódio. Esse aspecto tem importância, ao compreendermos que, no processo de aquisição da escrita, a criança escreve ao imitar a escrita de outrem. Dessa forma, a imitação é uma forma de escrita que ilustra o processo de aquisição da escrita pela criança.

Ainda que a silabação tenha sido imitada, a imitação não foi da mesma natureza, pois a pesquisadora silabou ao escrever, enquanto Mariana silabou ao ler. Isso revela que, no processo de mediação, a significação do Outro não foi incorporada pela criança tal como ocorre. $\mathrm{Na}$ ação de silabar a palavra, podemos inferir que a significação da escrita atribuída pela pesquisadora foi a de que a escrita representa a fala, já que escreveu tendo como referência a sua fala. Por sua vez, Mariana sugere que atribuiu outro sentido à ação observada - o sentido de que a escrita é confirmada quando é lida, ou seja, para haver escrita, é necessário ler. Isso sugere que Mariana compreende a escrita como uma forma de representação. Essa passagem demonstra que o processo de mediação não foi imediato.

Nesse episódio, a significação poderia ser diferente, se a pergunta da pesquisadora fosse: "Mariana, você escreveu?". Ou: "O que você escreveu?". Talvez as respostas de Mariana fossem outras. Por exemplo, ao perguntar, "Mariana você escreveu?", ela poderia responder que não. Com isso, queremos explicitar que detalhes da atuação pedagógica, como uma pergunta, conferem diferentes significaçóes do Outro e podem levar a criança a atribuir diferentes sentidos à escrita; diferentes perguntas podem resultar em diferentes sentidos à escrita, uma vez que exigem da criança diferentes formas de pensar. 
É possível observar outro aspecto da atribuição de sentido à escrita por Mariana: quando a pesquisadora solicitou escrita à criança, e esta traçou linhas, é possível compreender que Mariana atribuiu o sentido de que a escrita é representada por linhas (símbolos e signos específicos).

O episódio, na íntegra, evidencia a insistência da pesquisadora em dizer à Mariana "escreva" e, somente ao final do episódio, percebeu e considerou as açôes de Mariana como forma de escrita. Nesse sentido, pode-se perceber como é complexo o processo de inserir ou perceber a inserção de uma criança na proposta de escrita.

Ainda que observados alguns sentidos atribuídos à escrita por Mariana, não foi notado o aspecto principal do processo de aquisição da escrita pela criança: a necessidade de escrever. Desde o início do episódio, ao solicitar brincadeira, Mariana não mostrou interesse pela escrita, embora tenha escrito. Em acréscimo, sua escrita exigiu-lhe a representaçáo de uma ideia da pesquisadora, e não de Mariana. A criança não participou, não foi inserida no processo de elaboração da ideia, no momento da escrita, conforme explicita a passagem a seguir. "Pesquisadora: vamos escrever que o cachorro foi o primeiro ser vivo a viajar para o espaço [...] Escreve aí no seu [na sua folha]". Desse modo, entendemos que a pesquisadora fez por Mariana e não com ela. Ao compreender a escrita em sua forma final como função psíquica superior, um instrumento que serve também à expressão de ideias e que, na área da deficiência intelectual, o desenvolvimento das funções psíquicas superiores deve ser priorizado em relação ao desenvolvimento das funçóes elementares, diante da passagem apresentada, cabe questionamentos: dizer à Mariana o que escrever e não solicitar a ela uma ideia do que escrever pode promover o desenvolvimento de funçóes psíquicas superiores?

Nessa passagem, consideramos que a pesquisadora não atuou sobre o desenvolvimento das funçóes adequadas, de modo que não permitiu a Mariana atribuir à escrita o sentido de representação de ideias. Assim, a atuação pedagógica não contemplou a vivência da escrita como uma necessidade, pois não ocorreu como desejo de expressão de Mariana.

Apesar de o assunto escrito ser de interesse de Mariana, náo se constatou o seu interesse pela escrita, portanto, não houve atribuição do principal sentido à escrita: a escrita como uma necessidade de expressão da criança. Isso deve ser compreendido em estreita relação com a atuação pedagógica, na qual a escrita não foi significada como uma necessidade. 
Nesse episódio, foi possível compreender que Mariana atribuiu à escrita diferentes sentidos: que a escrita é uma forma de representação por linhas (e não por outras ações, sendo, por isso, uma representação por um sistema especial de signos e símbolos); que a escrita é uma representação também porque deve ser lida para ser compreendida; e que a escrita náo é sua atividade principal. Com isso, consideramos quão complexo é o processo de aquisição da escrita e os diversos aspectos que precisam ser considerados.

\section{Conclusão}

Ao descrevermos esse episódio buscamos demonstrar que os sentidos atribuídos à escrita por Mariana estiveram diretamente relacionados com a significação da escrita, no atendimento. Nessa perspectiva, compreendemos que só é possível pensar e discutir sobre os sentidos atribuídos à escrita por uma criança, quando a significação do Outro é focalizada. Sem a relação entre significação e sentido, ou seja, sem compreendermos o processo de mediação, a atribuição de sentidos não pode ser compreendida.

Assim, os sentidos atribuídos ou não à escrita pela criança só podem ser compreendidos ao considerarmos diferentes aspectos do processo de mediaçáo. Focalizar apenas a criança nos oferece uma visáo parcial do processo de aquisiçáo da escrita, o que pode impedir de pensar e repensar adequadamente o ensino - que é aspecto fundamental dos processos educativos, e náo apenas a aprendizagem, como muitas vezes ocorre.

Por fim, podemos afirmar que a criança pequena com síndrome de Down atribui sentidos à escrita desde que vivencie essa linguagem. Portanto, é necessário que essa criança vivencie a escrita desde a Educação Infantil para que essa linguagem faça parte do seu desenvolvimento.

\section{Notas}

${ }^{1} \mathrm{O}$ conceito de esferas cotidianas e não cotidianas é discutido por Newton Duarte (1996), em Educação Escolar, teoria do cotidiano e escola de Vigotski.

${ }^{2}$ Neste texto, utilizamos publicaçôes desses autores editadas a partir dos anos de 1990. 
${ }^{3}$ Prestes (2010) explica que o conceito de "zona de desenvolvimento iminente" foi traduzido para a língua portuguesa como "zona de desenvolvimento proximal", "zona de desenvolvimento imediato" e "nível potencial de desenvolvimento". A autora defende a utilização da expressão "zona de desenvolvimento iminente", ao compreender que essa é a tradução que mais se aproxima do conceito elaborado por Vygotski. Por isso, utilizamos essa expressão.

${ }^{4} \mathrm{O}$ leitor interessado na descrição detalhada do estudo deve reportar-se a Lopes (2011).

\section{REFERÊNCIAS}

AMERICAN ASSOCIATION ON MENTAL RETARDATION (AAMR). Retardo mental: definição, classificação e sistemas de apoio. 10 ed. Porto Alegre: Artmed, 2006.

ARCE, Alessandra; MARTINS, Lígia Márcia (Org.). Quem tem medo de ensinar na educação infantil: em defesa do ato de ensinar. Campinas: Alínea, 2007.

BONETI, Rita Vieira Figueiredo. A interpretação da escrita pela criança portadora de deficiência intelectual. Revista Brasileira de Educaçáo Especial, Marília, SP, v. 3, n. 5, set. 1999.

BRASIL. Lei n ${ }^{\circ}$ 9.394, de 20 de dezembro de 1996. Estabelece as diretrizes e bases da educação nacional. Diário Oficial da União, Brasília, DF, 23 dez. 1996.

Lei 11.274, de 6 de fevereiro de 2006. Altera a redaçấo dos artigos 29, 30, 32 e 87 da Lei 9.394, de 20 de dezembro de 1996, que estabelece as diretrizes e bases da educação, dispondo sobre a educação de nove anos para o ensino fundamental, com matrícula obrigatória a partir dos seis anos de idade. Diário Oficial da União, Brasília, DF, 6 fev. 2006.

Ministério da Educação. Secretaria de Educação Especial. Política nacional de educação especial na perspectiva da educação inclusiva. Brasília, DF, 2008. 
CARLO, Marysia Mara Rodrigues do Prado. Se essa casa fosse nossa: instituições e processos de imaginação na educação especial. São Paulo: Plexus, 2001.

DUARTE, Newton. Educação Escolar, teoria do cotidiano e escola de Vigotski. Campinas, SP: Autores Associados, 1996.

FERREIRA, Maria Cecília Carareto. A escolarização da pessoa com deficiência mental. In: LODI, Ana Claudia Balieiro et al. Letramento e minorias. 2. ed. Porto Alegre: Mediação, 2002. p. 98-103.

GÂNDARA, Viviane Santos. Caminhos trilhados na compreensão da representação escrita por uma criança com sindrome de Down: um estudo de caso. 2005. Dissertação (Mestrado em Educação) - Universidade do Vale do Itajaí, Itajaí, SC, 2005.

GOMES, Adriana Leite Limaverde. Leitores com sindrome de Down: a voz que vem do coração. 2001. Dissertação (Mestrado em Educação) Universidade Federal do Ceará, Fortaleza, 2001.

IDE, Sahda Marta. Alfabetização e a deficiência mental. Revista Brasileira de Educação Especial, Marília, SP, v. 1, n. 1, p. 51-63, 1992.

KRAMER, Sônia. A política do pré-escolar no Brasil: a arte do disfarce. 8. ed. São Paulo: Cortez, 2006.

LEITE FILHO, Aristeo. Proposiçóes para uma educaçáo infantil cidadá. In: GARCIA, Regina Leite; LEITE FILHO, Aristeo (Org.). Em defesa da educação infantil. Rio de Janeiro: DPJA, 2001. p. 29-58.

LEONTIEV, Alexis. Nikolaevich. Uma contribuição à teoria do desenvolvimento da psique infantil. In: VIGOTSKII, Lev Semenovich; LURIA, Alexander Romanovich; LEONTIEV, Aléxis Nikolaevich.

Linguagem, desenvolvimento e aprendizagem. 10. ed. São Paulo: Ícone, 2006. p. 59-83.

LIMA, Elieuza Aparecida de. Infância e teoria histórico-cultural: (des) encontros da teoria e da prática. 2005. Tese (Doutorado em Educação) Faculdade de Filosofia e Ciências, Universidade Estadual Paulista, Marília, SP, 2005. 
LIMA, Elieuza Aparecida de. A escrita na educação infantil: contribuições da Teoria Histórico-Cultural. In: JORNADA DO NÚCLEO DE ENSINO DE MARÍLIA: Teoria Histórico-Cultural: objetivações contemporâneas para o ensino, a aprendizagem e o desenvolvimento humano, 7., 2008, Marília. Anais eletrônicos... Marília: Faculdade de Filosofia e Ciências da Universidade Estadual Paulista, 2008. 1 CD-ROM.

LOPES, Ingrid Anelise. Os sentidos atribuidos à escrita por uma criança pequena com sindrome de Down: um estudo a partir de atuação pedagógica na educação infantil. 2011. Dissertação (Mestrado em Educação) - Faculdade de Filosofia e Ciências, Universidade Estadual Paulista, Marília, SP, 2011.

LURIA, Alexander Romanovich. O desenvolvimento da escrita na criança. In: VIGOTSKII, Lev Semenovich; LURIA, Alexander Romanovich; LEONTIEV. Alexis Nikolaevich. Linguagem, desenvolvimento e aprendizagem. 10. ed. São Paulo: Ícone, 2006. p. 143-189.

MELLO. Suely Amaral. Uma reflexão sobre o conceito de mediação no processo educativo. Teoria e prática da Educação, Maringá, PR, v. 6, n. 12, p. 29-48, 2003.

MELLO. Suely Amaral. A apropriação da escrita como um instrumento cultural complexo. In: MENDONÇA, Sueli Guadelupe de Lima; MILLER, Stela (Org.). Vigotski e a escola atual: fundamentos teóricos e implicaçóes pedagógicas. Araraquara: Junqueira Marin, 2006. p. 181-192.

MERCADO, Elisangela Leal Oliveira. A criança com síndrome de Down e a possível construção da base alfabética. Educação: Revista do Centro de Educação da UFAL, Maceió, v. 12, p. 30-47, 2000.

MERISSE, Antônio et al. Lugares da infância: reflexôes sobre a história da criança na fábrica, creche e orfanato. São Paulo: Arte \& Ciência, 1997.

MUKHINA, Valeria. Psicologia da idade pré-escolar: um manual completo para compreender e ensinar a criança desde o nascimento até os sete anos. São Paulo: Martins Fontes, 1995.

OLIVEIRA, Anna Augusta Sampaio de. Um diálogo esquecido: a vez e a voz de adolescentes com deficiência. Londrina: Praxis; Bauru: Canal 6, 2007. 
PADILHA, Anna Maria Lunardi. Práticas pedagógicas na educação especial: a capacidade de significar o mundo e a inserção social do deficiente mental. 2. ed. Campinas: Autores Associados, 2005.

PINO, Angel. As marcas do humano: às origens da constituição cultural da criança na perspectiva de Lev S. Vigotski. São Paulo: Cortez, 2005.

PINTO, Gláucia Uliana.; GÓES, Maria Cecília Rafael de. Deficiência mental, imaginação e mediação: um estudo sobre o brincar. Revista Brasileira de Educação Especial, Marília, SP, v. 12, n. 1, p. 11-28, 2006.

PRESTES, Zoia Ribeiro. Quando não é quase a mesma coisa: Análise de traduçóes de Lev Semionovitchi Vigotski Repercussóes no campo educacional. 2010. Tese (Doutorado em Educação) - Faculdade de Educação, Universidade de Brasília, DF, 2010.

SCHWARTZMAN, José Salomão. Síndrome de Down. São Paulo: Memnon, 1999.

VALIENGO, Amanda. Educação infantil e ensino fundamental: bases orientadoras à aquisição da leitura e da escrita e o problema da antecipação da escolaridade. 2008. Dissertação (Mestrado em Educaçáo) - Faculdade de Filosofia e Ciências, Universidade Estadual Paulista, Marília, SP, 2008.

VIEIRA, Rosana. A pré-história da escrita na idade pré-escolar: contribuiçôes da teoria histórico-cultural. 2006. (Mestrado em Educação) - Universidade Federal de São Carlos, São Carlos, SP, 2006.

VYGOTSKI, Lev Semenovich. Obras escogidas II. Madri: Visor, 1993.

VYGOTSKI, Lev Semenovich. Obras escogidas III: Problemas del desarrolo de la psique. Madri: Visor, 1995.

VYGOTSKI, Lev Semenovich. Obras escogidas IV: Fundamentos de defectologia. Madri: Visor, 1997.

VYGOTSKY, Lev Seminovich. The problem of the environment. In: VALSINER, Jaan; VEER, Rene Van Der (Org.) The Vygotsky Reader. Cambridge e Oxford: Blackwell, 1994, p. 338-354. 


\section{Algunos aspectos del proceso de adquisición de la escritura de un niño pequeño con síndrome de Down}

\section{Resumen}

La cultura es el contenido de la Educación Preescolar y debe ser enseñado a través de la planificación educativa y los procedimientos apropiados para los niños pequeños, proporcionando, en la medida de lo posible, experiencias delosinstrumentos de la cultura. Estas experiencias permiten el pleno desarrollo de todos los niños. Esto incluye a niños con necesidades educativas especiales derivadas de síndrome de Down. Entre otros instrumentos de la cultura, el niño pequeńo necesita de experimentar la escritura para empezar su proceso histórico de adquisición del lenguaje. Al observar niños con síndrome de Down que no podían experimentar la escritura en Educación Preescolar, se inició una investigación, basada en la Teoría Histórico-Cultural, con el objetivo de describir y comprender los significados atribuidos a la escritura por un niño pequeńo con síndrome de Down. Los datos fueron recolectados a través de los registros escritos a partir de las experiencias de este niño con la actuación de algunos de los investigadores. Los registros se realizaron en las sesiones de Servicio de Apoyo a la Educación, y fueron
Some aspects about the acquisition of the writing process by a young child with Down syndrome

Abstract

The Culture is the content of early childhood education, which should be taught through pedagogic planning and appropriate procedures for young children, among which we highlight the experience of needing the instruments of culture. Such experiences allow the full development of all children. This includes children with special educational needs resulting from Down syndrome. Among other instruments of culture, small children need to experience the writing to initiate the historical process of this language acquisition. Observing children with Down syndrome out of the experiences of writing in early Childhood Education, we conducted an investigation based on Historical-Cultural Theory, in order to describe and understand the senses attributed to writing, by a small child with Down syndrome. Data were collected through records from the experiences of writing of this child during the acting of one of the researchers. The acting took place in sessions of the Pedagogical Support Services, which were filmed with the help of research assistants, and later the films were observed and described for the selection of episodes to be discussed. The data were presented and discussed in order to understand possible attributed senses to the writing by the child. The results indicate that the child may attribute senses 
filmados con la ayuda de asistentes de investigación, y posteriormente observados y descritos para la selección de los episodios que debían discutirse. Los datos fueron presentados y debatidos con el fin de comprender los posibles significados atribuidos a la escritura por los niños. Los resultados indican que el niño daba sentido a la escritura, y que este sentido está directamente relacionado con el significado de la escritura propuesta por el investigador. Así, fue posible comprender que los significados atribuidos a la escritura por el niño están estrechamente relacionados con el proceso de mediación.

Palabras claves: Educación Preescolar. Escritura. Síndrome de Down.

\section{Ingrid Anelise Lopes}

E-mail: ingrid_anelise@usp.br

\section{Anna Augusta Sampaio de Oliveira}

E-mail: anna64.oliveira@gmail.com to the writing, and such assignment was directly related to the meaning of writing by the researchers in the attendances. Thus it was possible to understand that the senses attributed to the writing are closely related to the mediation process.

Keywords: Early Childhood Education. Writing. Down Syndrome.

Enviado em: 5/9/2012

Versão final: $18 / 3 / 2014$

Aprovado em: 26/3/2014 